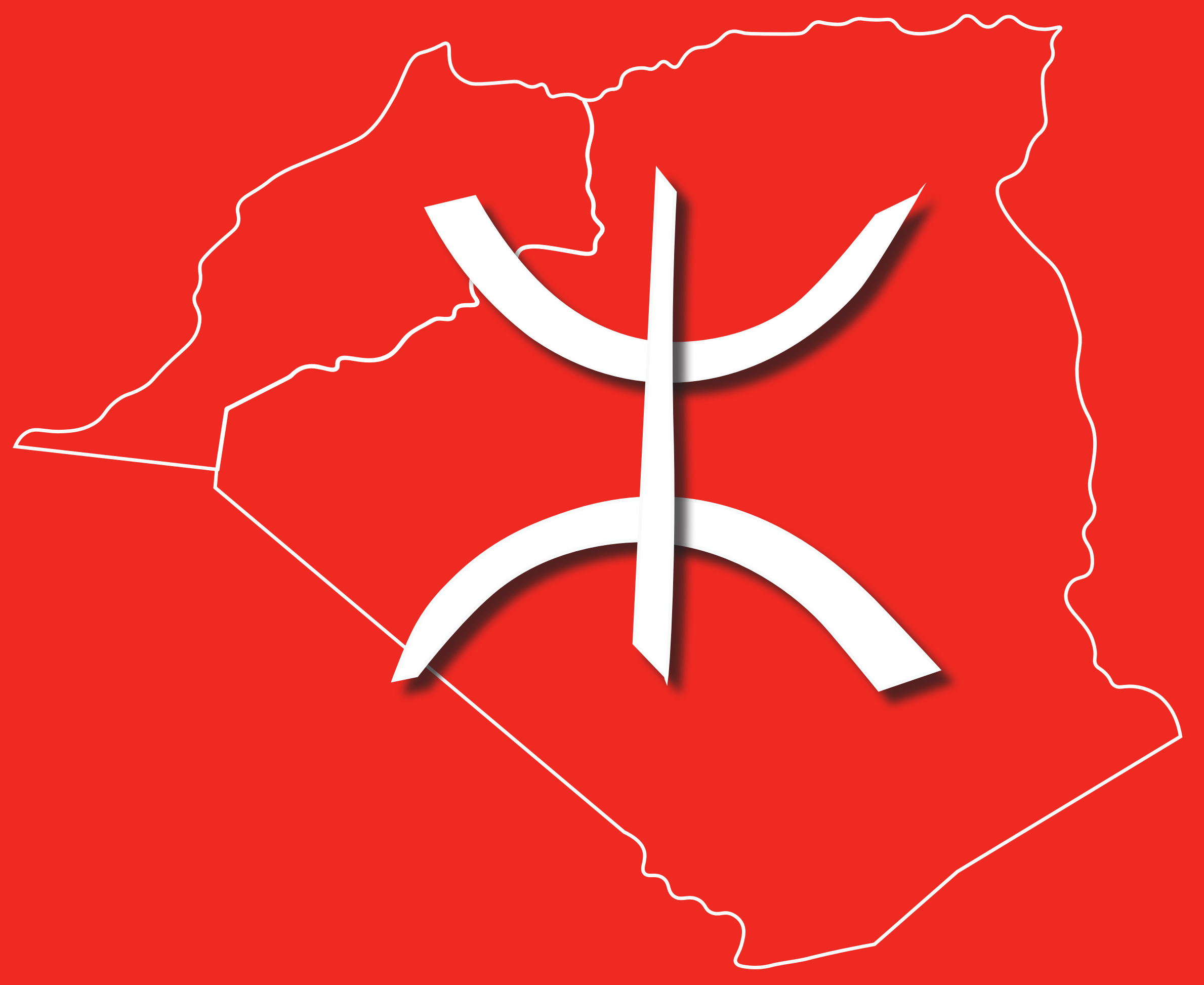

\title{
Political Discourse in the Maghreb: \\ An Analysis of Amazigh Identity in Algeria and Morocco
}

Peter MacDonald

Edited by Shira Garbis and Isha Shahané

ABSTRACT - The Imazighen (plural of Amazigh) are an indigenous group primarily located in Northern and Western Africa. While Amazigh communities are present across the Maghreb, the role of Amazigh identity in Morocco and Algeria is of particular interest given each country's distinct treatment of ethnic and linguistic minorities. In Algeria, Amazigh identity is not as overtly politicized as in Morocco, wherein Amazigh communities are often at the forefront of public discourses and are often scapegoated as a source of political instability. Compared to Morocco, Algerian Imazighen generally experience higher acceptance levels due to numerous social, political, historical, and geographic factors that underpin the treatment and perceptions of Amazighté in Morocco and Algeria today. This article analyzes Algeria and Morocco's respective independence movements, political systems, language laws, and geographic topography to link the contemporary role of Amazigh identity to each national setting's unique history, politics, and geography. 
he Imazighen are an ethnic group indigenous to North Africa whose existence predates modern Arab society; though they are sometimes referred to as "Berbers," this term is rooted in colonial sentiments and has largely been repurposed by Amazigh communities (El Aissati 2001, 58). Many Imazighen currently live in dispersed communities across North Africa, primarily in Morocco and Algeria. While both countries have large Amazigh demographics, there exists a sharp difference between each country's political frameworks and incorporation of Amazigh identity. The Moroccan government has been less accepting of Amazigh communities than Algeria's, leading Amazigh activists in Morocco to become more politicized. It is worth noting that, for this paper, I define politicization as the degree to which something has been transformed from an objective, nonpartisan entity into a politically charged, often subjective one. Politicization does not take place in a vacuum, and it often reflects myriad socio-political pressures. More specifically, Amazigh communities in Morocco are frequently scapegoated for political instability, making their "role" in contemporary Moroccan society inherently salient, albeit in an ostensibly negative manner. On the other hand, present-day Algerian society is relatively accepting of Amazigh minorities, who are increasingly integrated into political discussions. Historical context, geographical differences, varying civil society groups, and differing degrees of language acceptance can explain why Amazigh communities are more politicized in Morocco than Algeria. Moreover, these factors can effectively account for why Amazigh identity is considered less transgressive in Algeria and why Amazigh communities are politically ostracized in Morocco and depicted as counter-establishment agitators. Firstly, while Algeria's path to independence was marred by persistent French colonial rule and a bloody civil war, Morocco gained independence through a relatively quick process. Algeria's lengthy experience under French rule inadvertently resulted in a more unified population, staunchly resistant to imperial sentiments. This difference in history can further account for the contrasting political developments in Algeria and Morocco, respectively. society organizations facilitating the protection of Amazigh heritage, and the unyielding Moroccan monarchy quashes many attempts by Imazighen to self-organize (Chtatou 2019). Due to the primacy of the monarchy-which derives its authority from Islam-in Moroccan politics, Amazigh communities are often scapegoated, as they are accused of being inherently opposed to national unity (Silverstein 2012, 131). In addition to these historical and political factors, geography has played a crucial role in the gradual acceptance of Amazigh minorities in Algeria, many of whom have moved to find work in major cities. In contrast, the larger, more isolated Amazigh communities in Morocco remain relatively concentrated in the Sahara Desert and surrounding mountainous regions. Finally, the Amazigh language, known as Tamazight, politicized, also illustrates different perceptions

\section{Explanation of Amazigh Identity}

To understand how and why Algeria and Morocco treat Imazighen differently, it is first essential to establish the meaning of "Amazigh identity" and what constitutes Amazigh culture. Most Imazighen in North Africa are Sunni Muslim, though there are large enclaves of Christian and Jewish Imazighen in France, many of whom emigrated in the 1960s and 70s (El Aissati 2001, 60). Some contemporary Amazigh communities currently rely on farming and herding livestock in the mountainous regions of North Africa, whereas others are primarily nomadic. Their ancestral roots are in the Horn of Africa, but large numbers of Imazighen migrated westward across North Africa, settling in the area between Egypt and Mauritania Nomadic practices conthu to inform contemporary expressions of Amazigh culture, which is not spatially confined or isolated within sovereign borders. Moreover, the Amazigh do not closely resemble Central Africans or other "Arab" Muslims of the Middle East and North Africa; until the twentieth century, European settlers controversially referred to Imazighen as "Caucasoid" or "pseudo-white," suggesting their greater proximity to "whiteness" compared to their Arab counterparts (Fage \& Tordoff 2013, 155). Observations about the physical and cultural differences between Imazighen and Arabs have historically served as a basis for "othering" Amazigh communities as an ethnic group that is separate and distinct from the rest of the modern Arab World.

\section{Path to Self-Governance}

Algeria and Morocco's distinctive paths to independence help explain the differing roles played by Imazighen in their respective political spheres. Whereas Algeria experienced arduous French colonial rule throughout the nineteenth and twentieth centuries, Morocco was colonized later and for a shorter time. The institutions put in place by France in Algeria greatly affected the Amazigh communities and the lengthy French presence in Algeria also inadvertently caused the Amazigh people to band together with Arab people against their common enemy. Because Morocco evaded some of the unyielding, drawn-out colonial practices in Algeria, Amazigh and Arab Moroccans had fewer incentives to unify in the face of an external threat. Though both countries continued to "other" and oppress Amazigh demographics after the colonial era, this distinction helps explain why divisions between Arabs and Imazighen are currently more prominent in Morocco than Algeria and why they have been politicized to different degrees. Following France's annexation of Algeria in 1848, approximately 7 per cent (roughly 110,000 ) of the Algerian population was European (Hargreaves 1997, 41). Once the French had successfully captured and quelled all of presentday Algeria, they began implementing specific measures to fragment the native population. The French colonial government's main goal was to "eradicate Islam from the Algerian identity," while noting that "the Amazigh seemed keener to renounce their Muslim legacy, as they more closely resembled the French" (Calvet 2018). The perceived "whiteness" of Imazighen and France's strategic decision to rule over a divided populace the French government's relatively preferential treatment of Amazigh communities over Arab ones. Consequently, Amazigh tribal leaders were elevated to positions of authority in Algeria throughout the 1850s and 60s (Calvet 2018).

The French use of Imazighen as proxy leaders led to greater interaction between Amazigh communities and Arab ones. Though the privileges awarded to the "Caucasian" Imazighen were meant to drive a wedge between them and Arab Muslims, it also facilitated the diffusion of Amazigh identity and culture throughout Algeria. As Amazigh communities integrated into Arab ones, the amalgamation of cultures created a discursive landscape wherein the Algerian Amazigh could later advocate on behalf of their formal recognition. This early bondedness of Arab and Amazigh communities can explain why Imazighen are less politicized in contemporary Algeria than Morocco; the French colonial era forcibly unified different ethnic groups in Algeria that had previously lived in isolation from one another, and while said unification did not lead to immediate policy upheaval, it effectively laid the groundwork for future efforts by the Amazigh to gain cultural recognition in the decades that followed.

While Imazighen were considered "less Muslim," and therefore better candidates for integration into positions of authority and assimilation into French culture, the success of French divide and rule tactics in colonial Algeria were ultimately short-lived. By the late nineteenth century, many Amazigh communities had already started to openly defy French rule in tandem with Arab protests and organized political dissidence (Yezza 2013). Tensions in Algeria erupted shortly after World War Two, igniting a lengthy war of independence between French forces and the native Algerian population. The war, beginning in 1954, begat thousands of Algerian casualties as anti-colonial associations fought for the right to self-govern, which they finally achieved when an armistice was reached in 1962 (El Aissati 2001, 60). While issues of Amazigh recognition were not central to Algeria's 
war for independence, Amazigh identity gradually became more prevalent throughout Algeria during the war. The Imazighen, together with their Arab allies, worked to expel the Europeans during the war and later rebuilt the contemporary Algerian state (Yezza 2013). Struggle borne and necessity driven, the Amazigh of Algeria were critical in the dismemberment of French colonial establishment that had plagued the country for over a century. Through years of struggle and resistance to French colonial rule, as well as their assigned role in French efforts to suppress Arab identity, Amazigh people and their culture became effectively entrenched in the fibre of modern Algeria. Once the French were expelled from Algeria, Algerian politics became increasingly prone to animosity as the government was forced to rebuild itself; these tensions culminated in violent outbursts between Amazigh communities and Arab ones. However, the gradual reconciliation of some of these factions has led to greater recognition of Amazigh identity. Amazigh identity is not wholly accepted in Algeria today, but important landmarks in the history of Algeria - such as the War of Independencecan account for why Imazighen are relatively more accepted and less politicized in Algeria.

While the story in Algeria is one of a historically rooted, inextricable - though not lways amicable- linkage between Imazighen always a nicable- linkage betwe and Arab demorocco throughout the nineteenth and twentieth centuries was relatively different. Prior to European expansion into North Africa in the late 1800s, Morocco was ruled by a series of dynasties with a Sultan as the official head of state (Seligman 1930, 145). France, along with Britain and Spain, used political maneuvers to occupy Morocco, subordinating the Sultan to a figurehead status (Fage and Tordoff 2013, 469). While France effectively secured Morocco in 1912, Algeria became a French colony over 80 years before. These differing time horizons during the colonial era meant that French influence and control was much less prominent in Morocco.

Since France lacked the time to fully consolidate its presence in Morocco-the First World War broke out just two years later in 1914Amazigh communities were not integrated into
Moroccan Arab spheres to the same extent as they were in Algeria. The remainder of the French occupation in Morocco was similarly undercut by the Great Depression in the 1930s and the Second World War in the 1940s, during which France was occupied with domestic crises, precluding its ability to thoroughly occupy Morocco. By late 1956, Morocco gained full independence from both France and Spain without resorting to rem armed conflict, which was necessary in Algeria (Silverstein 2012,131). Morocco established itself
as a constitutional monarchy under the popular Sultan Mohammed V as the official head of state (Fage and Tordoff 2013, 563). Morocco's largely non-violent struggle for self-rule did not yield the ame level of Arab-Amazigh cooperation as it did in Algeria. Accordingly, Amazigh identity was not embedded into Moroccan society throughout the nineteenth and twentieth centuries since there was no colonial enterprise or modern nationbuilding project that warranted a unified populace.

$$
\text { While both Algeria and Morocco endured }
$$
French colonial leadership, their respective experiences under colonial rule impacted Amazigh communities differently. Amazigh identity is more acceptedincontemporaryAlgeriaasAmazighculture was compelled to mix with Arab culture throughout the twentieth century to resist French colonial rule. the formal recognition of Amazigh identity since the Algerian government essentially had to rebuild its governmental institutions, it would serve as a precursor for Amazigh-Arab relations in the decades that followed. It is also important to note that, even though French colonial rule provided a framework for greater Arab-Amazigh unity in Algeria, the formal recognition of Amazigh identity was not an immediate consequence of the War of Independence. Rather, this colonial legacy resurfaced in the decades that followed amid state efforts to Arabize Algerian society at the expense of minority demographics, ultimately allowing Algerian Imazighen to mobilize and reassert their presence in the national political sphere. Conversely, the lack of prominent French rule in Morocco precluded the same level of integration, both during and after the colonial era. Thus, each country's path towards independence can account for why the Imazighen became more politicized in Morocco during the second half of the twentieth century.

\section{Topography and Demographics of the}

\section{Region}

In addition to Morocco and Algeria's respective paths to independence, their unique trajectories towards the increased acceptance of Amazigh minorities can be further illustrated by topography and demographic divides. In Algeria, large proportions of the Amazigh population live in the Atlas Mountains that spread across North Africa. However, an even larger number of Imazighen live in cities, alongside the Arab majority (Silverstein 2009, 170). In Morocco, Amazigh and Arab communities were not induced to integrate during the nineteenth and twentieth centuries to the same extent as their Algerian counterparts, given that neither the French colonial government nor the Moroccan monarchy initiated centralization or unification efforts. The prolonged bifurcation between Morocco's Amazigh and Arab demographics has profoundly impacted the living situations of Imazighen in contemporary Morocco, the vast majority of whom live in scattered "tribes," extending from mountains and valleys to the Western-most regions of the Sahara Desert bordering Algeria and Morocco (Silverstein 2009, 173). Furthermore, the three wealthiest cities in Morocco and on the African continentTangier, Marrakesh, and Casablanca-located along Morocco's North-Western coast, all carry significant political clout, though none of them are home to substantial numbers of Amazigh residents (Silverstein 2009, 170). Taken together, these geographic factors, and the varying degrees of dispersion of the Amazigh populations in Algeria and Morocco, have greatly impacted the degree to which Imazighen are accepted in each country.

The French occupation of Algeria allowed for a more extensive diffusion of Amazigh culture across the North African country. Because the French instituted Amazigh citizens as local leaders, many Amazigh communities travelled from their relatively secluded homes to cities that were predominantly populated by Arab citizens (Calvet 2018). One of the largest Amazigh groups in Africa, the Kabyle, have occupied the mountainous landscape of Northern Algeria for centuries. The region from which they get their namesake, Kabylia, was, and continues to be, particularly relevant as it is the birthplace of the Amazigh cultural renaissance and the Berber Spring of 1980. In spite of Kabylia's significance - and that of similar mountainous regions - in the articulation of Amazigh culture, during the French occupation and the subsequent quest for independence, many Kabyle communities migrated southward into cities like Algiers, where Imazighen are estimated to constitute over 50 per cent of the population (Encyclopædia Universalis). With such an undisputable presence in the nation's capital, it is impossible for the Algerian government to wholly disregard issues of Amazigh importance. Indeed, early efforts to do so during the 1960 s and 1970 s proved unsustainable, contributing to the increased politicization of the Amazigh cause since the 1980 s. It is important to recall, however, that while Imazighen are recognized throughout the country, this placid acceptance does not necessarily translate to political leverage. Amazigh people in Algeria may not be overtly politically ostracized today, but that does not mean that they carry political clout that is comparable to that of their Arab counterparts in the region. French occupation was neither persistent nor fully realized in Morocco. As such, Amazigh communities had fewer incentives to integrate with Moroccan Arabs at the time. This led the majority of Amazigh communities to remain in their ancestral homes, far removed from the predominantly Arab cities of coastal Morocco (Silverstein and Crawford 2004, 47). Some groups in the country have tried - with little success - to connect these scattered Amazigh communities with the Arab government at large. Most notably, the Movement Populaire, a political party that does not "identify itself strictly as representative of the Amazigh but rather of Moroccan rural people," strives to represent marginalized Imazighen who are afforded limited political representation due to their rural status (UNHCR). The relative lack of interdependence between Moroccan 
Imazighen and Arabs is a significant obstacle stymieing effective political representation for Amazigh communities. For instance, most highranking officials who are capable of influencing national politics and the economy live in coastal cities like Marrakesh or Tangier, and are therefore more likely to overlook Amazigh interests and concerns. Moreover, the two ethnic groups are separated by a complex topography of desert and mountains, the and mountains, the likes of which represent additional divides between the two cultures. The geographical separation of the Imazighen and Arab Moroccans has allowed the central government to shun Amazigh identity under the banner of "otherness," making it all the more politicized.

The demographic makeup of key political cities in Algeria, such as Algiers, is distinctly more Amazigh due to the country's history. Meanwhile, in contemporary Morocco, Amazigh grievances can more easily be disregarded as rural and "tribal" issues given the limited Amazigh presence in politically significant cities such as Marrakesh and Casablanca. The lack of Amazigh representation in the Moroccan government allows policy makers to scapegoat the Amazigh for political inefficiency (Silverstein 2012, 131). Amazigh people in Morocco are regularly depicted as being political agitators, insurgents, and renegades whose morals are not closely aligned with those of the Arab elites. Comparably, Amazigh communities in Algeria are not politicized to the same degree and they are more integrated into public discourses and policy decisions.

\section{Political Organization}

Along with the historical and geo-political underpinnings of contemporary disparities between Imazighen and Arabs in North Africa, Algeria and Morocco's political frameworks have also contributed to the degree to which Amazigh identity has been able to achieve recognition. While Algerian society continues to grapple with issues of Amazigh acceptance (carrying the Berber flag is still met with hostilities in some regions), the Moroccan political system, which remains deeply connected

to the monarchy, is generally less accepting towards Amazigh identity compared to Algeria. While neither country's governments formally recognize the existence of explicitly Amazigh political parties, Amazigh civil society groups are permitted in contemporary Algeria. Collectives such as the Rally for Culture and Democracy (RCD) and the Mouvement Culturel Berbère (MCB) are able to, "advocate for greater recognition and acceptance of a distinct Amazigh cultural and linguistic identity and the protection of Amazigh human and legal rights" (Chtatou 2019). This acceptance of non-Arab identity in Algeria is largely due to the country's recent, brutal civil war that ended less than 20 years ago; with its associated destruction still in the collective memory of Algerian society, the government is more careful, and it conducts itself in such a way so as not to anger minority groups. In addition, some parties in Algeria are able to indirectly cater to Imazighen without being banned outright. One of these parties, the Socialist Forces Front, even has four seats in the Council of the Nation and 14 seats in the People's National Assembly - the two chambers of Algeria's legislature (El Aissati 2001, 65). Following the Algerian Civil War, Algerians sought an agreement to better reconcile the country's political system with its constitution. One outcome of the civil war was the Sant'Egidio platform of 1995, formed by opposition parties and adopted largely by the Socialist Forces Front, the aforementioned Amazigh-sympathetic party. The goal of the platform was to bring about a more inclusive civic discourse, embracing Arab and nonArab identities alike (Naylor 2000). The Algerian Civil War thus had a profound impact on domestic politics, planting the seeds for further mobilization during the Arab Spring. In the aftermath of the Arab Spring, Amazigh grievances were similarly recognized as being critical to national stability, albeit in a more diminished capacity than Arab ones (Maddy-Weitzman 2015, 2500). During the periods of reconstruction that have taken place in Algeria over the last two decades, Amazigh issues have remained a topic of interest in the country. Algeria's history, coupled with its political structure —one that permits the existence of informal Amazigh parties and Amazigh civil society groups - have contributed to a latent acceptance of Amazigh identity in the country. In Morocco, the perceived "role" of Imazighen is one of insubordination and political unrest. The political sphere in Morocco is less accepting of Amazigh communities, which has led Amazigh identity to be politicized and equated with civil unrest. The overt, political ostracization of Amazigh communities in Morocco began during the $1960 \mathrm{~s}$ and $70 \mathrm{~s}$, when an era of social reform swept across the Middle East and the ideology of Arabization began to take shape. The notion of a Pan-Arabic identity was particularly popular in Morocco where "the hegemonic narrative propagated by ruling elites advocated for the full Arabization of society and the reduction of Berber culture to folklore status" (Maddy-Weitzman 2012, 109). The Moroccan governments desire to conform to a Pan-Arabic identity led to the othering of Amazigh communities and other minority groups. Since the mid-twentieth century, Amazigh identity has been politicized further, as protestors in Morocco often don Amazigh flags as a symbol of government resistance and counter-establishment ideals (Chtatou 2019). These protestors are often arrested publicly, causing Amazigh culture to be further scapegoated and depicted as a source of political instability (Maddy-Weitzman 2012, 113). Even though around 50 per cent of Morocco is believed to be Amazigh, the Arab elites of the country have persistently sought the installation of Arabization policies in government and the political fibre of the country. Amazigh identity in Morocco is suppressed, subdued, and politicized; Amazigh communities are seen as subservient to Arab ones (Chtatou 2019). Whereas the Imazighen in Algeria are included in political discussions, Amazigh communities in Morocco are rarely recognized. In addition, while political parties in Algeria are allowed to cater to Amazigh interests, the Moroccan government ignores the Imazighen and their identity unless it is being used as part of a political protest.

Politicization of the Amazigh Language The differing degrees of Amazigh- policitization present in Algeria and Morocco can also be explained by each country's willingness to formally recognize Tamazight, the predominant Amazigh language. While neither country has wholly integrated Tamazight into the socio-political realm, the Algerian government permits the use of Tamazight more so than itsMoroccan counterpart.

The politicization of Tamazight is an incredibly relevant topic in Algeria. Although the Algerian government recognized Tamazight as its second official language in 2016, this ostensibly progressive reform remains largely aspirational. Two years later, in 2018, the Algerian parliament vetoed an amendment that would have formalised the teaching of the Tamazight language in local schools. The rejection of Tamazight was met with protests by students and other activists who wanted the Algerian government to fund the teaching of Tamazight formally (Kestler-D'Amours 2017). This incident exemplifies how Amazigh identity continues to be politicized in Algeria despite the many improvements that occurred since its independence from France in 1962. However, it also illustrates Amazigh activists' capacity to protest decisions that negatively impact their community. In addition, the very presence of a referendum on Tamazight effectively illustrates the recognition that Amazigh identity is allotted in Algeria.

Compared to Algeria, the Moroccan government has proved to be more unyielding towards Amazigh communities, especially in the contexts of peaceful protests and language recognition. Protests in Morocco that call for advancements in the Amazigh language are typically met with immediate, sometimes violent police suppression. Government space, school classes, and office meetings must be conducted exclusively in Arabic, and the use of Tamazight in public can even lead to arrest (Chtatou 2019). Amazigh identity is extremely politicized in Morocco, so it is no surprise that the Amazigh language is similarly suppressed and ostracized. Although the Moroccan government ostensibly made strides regarding the acceptance of Amazigh identity and language in recent years, in reality, Amazigh identity is still heavily politicized in Morocco. Following the Arab Spring in 2011, the 
Moroccan monarchy recognized Tamazight, the language spoken by many native Amazigh people, as the second official language of Morocco (Sater 2011). While Moroccan law formally recognizes 2011). While Moroccan law formally recognizes
Tamazight, the language is at risk of extinction due to the ongoing politicization and vilification of it across North Africa (Ennaji 2014, 94). This vilification primarily reflects Mohamed VI's mandate that limited Tamazight to the traditional Tifinagh alphabet, thereby limiting its use and appeal compared to the Latin or Arabic scripts. This decision ultimately "domesticated the Amazigh cause" by relegating it to a smaller subset of the population (Sater 2011). The formal recognition of Tamazight in Morocco was borne out of the monarchy's desire advancing the Even though the monarchy recognized Tamazight, the language continues to be publicly shunned along with the Amazigh communities that speak it (Ennaji 2014, 95). While Tamazight is seen as theo and a threat to the Arabic language in both Algeria and Morocco, Amazigh communities in Algeria are allowed to protest their languagerelated grievances, whereas Amazigh communities in Morocco cannot. The degree to which the Algerian and Moroccan governments have rejected Tamazight illustrates an interesting overlap in the two cases; in both countries, it is socially unacceptable to conduct oneself in the second official language. While Imazighen in Algeria can typically contest the government's rejection of Tamazight with low to moderate success, Moroccan protestors are punished severely for speaking out. Neither country has fully accepted or embraced the use of Tamazight, though it has been formally recognized by both governments. Hence, the situation surrounding Tamazight is emblematic of the greater issues pertaining to the acceptance of Amazigh identity in the region.

\section{Conclusion}

As Amazigh identity is more politicized in Morocco than in Algeria, Moroccan Amazigh communities can influence societal discourse more significantly. In contemporary Algeria, where roughly 25 per cent of the population is believed to be of Amazigh descent, many Amazigh groups are currently pushing for increased cultural acknowledgement (Ennaji 2014, 96-97). Conversely, in Morocco, where as much as 60 per cent of the country is Amazigh, current political tensions can more often be attributed to Amazigh suppression and subsequent push-back. Overall, the Moroccan government has been less accepting of Amazigh communities, so theiri Amazigh communities, so their identity has become more politicized. In Algeria, tensions between Arabs and Imazighen are less apparent but still present. The differing treatment of Imazighen in Algeria and Morocco reflects four main factors. Firstly, and perhaps most importantly, each country's historical context, namely during the colonial era, illustrates how and why Amazigh identity plays a different role in each case. Additionally, Algeria and Morocco's unique geographic features have contributed to different perceptions of Amazigh communities by informing each country's contemporary demographic makeup Lastly Algeria and Morocco's respectiv and distinct frameworks for Amazigh-Arab relations, shaping Amazigh activists' capacity to advocate against language suppression. These factors can be synthesized to explain the varying ways Amazigh identity became politicized in Algeria and Morocco in society. Whereas Algeria's colonial past and centralized topography contributed to the gradual integration of Imazighen into contemporary political discussions, Morocco continues to suppress the expression of Amazigh identity, undermining the potential for multiculturalism 作 trajectories have similarly been informed by these differences, causing Amazigh communities to be more accepted in Algeria and more ostracized in Morocco. Moreover, while neither country readily embraced the Amazigh language of Tamazight, the Moroccan government has gone to greater lengths to ultimately subservient to Arabic. In light of these factors, it is clear that Amazigh communitiesand by extension other ethnic minoritiesare more politicized in Morocco than Algeria.

\section{References}

Aissati, Abderrahman El. 2001. "Ethnic Identity, Language Shift, and The Amazigh Voice in Morocco and Algeria." Race, Gender \& Class 8 (3): 57-69.

Calvet, Rosalie. 2018. "Silencing the Berbers." n.d. Accessed November 18, 2019. https://jhiblog.org/2018/01/29/silencing-theberbers/.

Chtatou, Mohamed. 2019. "The State of Amazigh Culture in Algeria and Morocco." n.d.

Accessed November 18, 2019. https:/ intpolicydigest.org/2019/01/31/the-state-ofamazigh-culture-in-algeria-and-moro $\mathrm{co} /$.

Chtatou, Mohamed. 2019. "The Amazigh Cultural Renaissance." n.d. Accessed November 5, 2020.https://www.washingtoninstitute.org/ policy-analysis/view/the-amazigh-cultural-ren issance.

Ennaji, Moha. 2014. "Recognizing the Berber Language in Morocco: A Step for Democratization." Georgetown Journal of International Affairs 15 (2): 93-99. www.jstor.org/stable/43773631

Fage, J. D, and William Tordoff. 2002. A History of Africa. 4th ed. London: Routledge.

Hargreaves, Alec, and Mark McKinney, eds. 1997. Post-Colonial Cultures in France. Taylor \& Francis Online. 1st ed. London: Routledge. https://doi-org.proxy3.library.mcgill. ca/10.4324/9781315004921.

"KABYLES - Encyclopædia Universalis." n.d. Accessed November 18, 2019. https://www. universalis.fr/encyclopedie/kabyles/.

Kestler-D’Amours, Jillian. 2017. “Algeria's Berbers Protest for Tamazight Language Rights."n.d. Accessed November 18, 2019. https://www.aljazeera.com/news/2017/12/ algeria-berbers-protest-tamazight-language-ri hts-171213185709684.html.

Maddy-Weitzman, Bruce. 2015. "A turning point? The Arab Spring and the Amazigh movement." Ethnic and Racial Studies, 38(14), 2499-2515. https://doi.org/10.1080/01419870.2015.10611 39
Maddy-Weitzman, Bruce. 2012. "Arabization and Its Discontents: The Rise of the Amazigh Movement in North Africa." The Journal of the Middle East and Africa 3 (2): 109-35. https:// doi.org/10.1080/21520844.2012.738549.

Naylor, Phillip Chiviges. 2000. France and Algeria: A History of Decolonization and Transformation. University Press of Florida.

"Overview of Middle East." n.d. Minority Rights Group. Accessed November 18, 2019.

https://minorityrights.org/minorities/overviewof-middle-east $/$.

Sater, James N. 2011. "Morocco's 'Arab’ Spring.” n.d. Middle East Institute. Accessed November 18, 2019. https://www.mei.edu/ publications/moroccos-arab-spring.

Seligman, C.S. 1930. "Races-of-Africa." n.d. Accessed November 18, 2019 https://ia801309.us.archive.org/35/items/ RacesOfAfrica/Races-of-Africa.pdf.

Silverstein, Paul. 2009. "The Cultivation of 'Culture' in the Moroccan Amazigh

Movement." Review of Middle East Studies 43 (2): 168-77.

Silverstein, Paul A. 2012. "A New Morocco? Amazigh Activism, Political Pluralism and Anti-Anti-Semitism.” The Brown Journal of World Affairs 18 (2): 129-40.

Silverstein, Paul, and David Crawford. 2004. "Amazigh Activism and the Moroccan State." Middle East Report, no. 233: 44-48. https:// doi.org/10.2307/1559451

Refugees, United Nations High Commissioner for. n.d. "Refworld | Morocco: Brief History of the Berbers Including Their Origins and Geographic Location.” Refworld. Accessed November 18, 2019. https://www.refworld.org/ docid/3df4be668.html.

Yezza, Hicham. 2013. "Beyond Arab vs Berber: The Rich Complexities of Algerian Identity Should Be Celebrated, Not Feared." n.d. OpenDemocracy. Accessed November 18, 2019.https://www.opendemocracy.net/en/northafrica-west-asia/beyond-arab-vs-berber-rich-c mplexities-of-algerian-identity-should-be-c/. 